\title{
Serum Prolidase Activity and Oxidative Stress in Diabetic Nephropathy and End Stage Renal Disease: A Correlative Study with Glucose and Creatinine
}

\author{
Akhilesh Kumar Verma, ${ }^{1}$ Subhash Chandra, ${ }^{2}$ Rana Gopal Singh, ${ }^{2}$ Tej Bali Singh, ${ }^{3}$ \\ Shalabh Srivastava, ${ }^{4}$ and Ragini Srivastava ${ }^{1}$ \\ ${ }^{1}$ Department of Biochemistry, Institute of Medical Sciences, Banaras Hindu University, Varanasi, Uttar Pradesh 221005, India \\ ${ }^{2}$ Department of Nephrology, Institute of Medical Sciences, Banaras Hindu University, Varanasi, Uttar Pradesh 221005, India \\ ${ }^{3}$ Division of Biostatistics, Department of Community Medicine, Institute of Medical Sciences, Banaras Hindu University, \\ Varanasi, Uttar Pradesh 221005, India \\ ${ }^{4}$ Department of Oral Pathology, Jaipur Dental College, Jaipur, Rajasthan 302020, India
}

Correspondence should be addressed to Ragini Srivastava; ragsriv@gmail.com

Received 15 July 2014; Revised 21 August 2014; Accepted 21 August 2014; Published 8 September 2014

Academic Editor: Emanuel Strehler

Copyright (C) 2014 Akhilesh Kumar Verma et al. This is an open access article distributed under the Creative Commons Attribution License, which permits unrestricted use, distribution, and reproduction in any medium, provided the original work is properly cited.

\begin{abstract}
Association of oxidative stress and serum prolidase activity (SPA) has been reported in many chronic diseases. The study was aimed at evaluating the correlation of glucose and creatinine to SPA and oxidative stress in patients with diabetic nephropathy (DN) and end stage renal disease (ESRD) concerned with T2DM. 50 healthy volunteers, 50 patients with T2DM, 86 patients with DN, and 43 patients with ESRD were considered as control-1, control-2, case-1, and case-2, respectively. Blood glucose, creatinine, SPA, total oxidant status (TOS), total antioxidant status (TAS), and oxidative stress index (OSI) were measured by colorimetric tests. SPA, TOS, and OSI were significantly increased in case- 1 and case- 2 than control-1 and control-2, while TAS was significantly decreased $(P<0.001)$. Blood glucose was linearly correlated to SPA, TOS, TAS, and OSI in control-2, case-1 and case-2 $(P<0.001)$. Serum creatinine was linearly correlated with SPA, TOS, TAS and OSI in control-2 and case-1 $(P<0.001)$. In case- 2 , serum creatinine was significantly correlated with SPA only $(P<0.001)$. Thus, the study concluded that SPA and oxidative stress significantly correlated with blood glucose and creatinine. SPA, TOS, TAS, and OSI can be used as biomarkers for diagnosis of kidney damage.
\end{abstract}

\section{Introduction}

Chronic kidney disease is one of the major health related issues of twenty-first century. Nephropathy constitutes a major microvascular complication of long term diabetes mellitus and it is the most common cause of end stage renal disease. It is categorized into five different stages. In stage one, the kidney function is normal and in stage two it is slightly reduced. Third and fourth stages are considered as incipient and overt diabetic nephropathy, respectively, while the last or fifth stage of diabetic renal disease is considered as end stage renal disease $[1,2]$. Hyperglycemia leads to altered level of non enzymatic protein glycation and glucotoxicity, activation of protein kinase $\mathrm{C}$ and increased activity of aldose reductase. These events enhance the production of thromboxane, growth factors, fibronectin and collagen type-IV as well as oxygen free radicals which induces the oxidative stress, resulting in the development and progression of complications of diabetes [3-5].

Prolidase (EC 3.4.13.9) activity is reported as a marker for oxidative stress for many diseases, like diabetes, diabetic neuropathy, nonulcer dyspepsia, chronic liver diseases, erectile dysfunction, osteoporosis, and so forth [6-11]. It cuts dipeptides with proline or hydroxyproline at C-terminal amino end $[12,13]$ and is involved in cell growth, collagen metabolism, and matrix remodeling [14]. Prolidase activity has been reported in plasma; leukocytes; erythrocytes; in various organs such as kidney and uterus; dermal fibroblasts; and thymus [7]. Very few studies on T2DM have been reported which are controversial with respect to serum 
TABLE 1: Representation of clinical parameters and demography for controls and cases.

\begin{tabular}{|c|c|c|c|c|c|}
\hline Parameter & Control-1 & Control-2 & Case-1 & Case-2 & $\begin{array}{l}\text { ANOVA } \\
\text { (F/Sig.) }\end{array}$ \\
\hline Number of subjects (total 229 subjects) & 50 & 50 & 86 & 43 & $\ldots$ \\
\hline \multirow{2}{*}{ Sex $(F=$ female, $M=$ male $)$} & F-20 & F-16 & F-39 & F-19 & \multirow{2}{*}{$\cdots$} \\
\hline & M-30 & M-34 & M-47 & M-24 & \\
\hline Age mean (in years) & $52.64 \pm 18.76$ & $53.34 \pm 14.68$ & $52.34 \pm 12.89$ & $57.34 \pm 15.36$ & $\begin{array}{c}F=1.16 \\
P=0.326\end{array}$ \\
\hline Duration of T2DM (in years) & Nil & $7.18 \pm 3.22$ & $11.14 \pm 3.18$ & $16.46 \pm 3.09$ & $\begin{array}{l}F=100.45 \\
P<0.001\end{array}$ \\
\hline Fasting blood glucose (FBS), mg/dL & $125.32 \pm 43.91$ & $191.26 \pm 38.24$ & $193.87 \pm 42.27$ & $218.91 \pm 39.54$ & $\begin{array}{l}F=46.01 \\
P<0.001\end{array}$ \\
\hline Postprandial blood glucose (PPBS), mg/dL & $130.68 \pm 47$ & $236.68 \pm 53.89$ & $236.17 \pm 23.79$ & $255.84 \pm 37.30$ & $\begin{array}{l}F=102.58 \\
P<0.001\end{array}$ \\
\hline Serum creatinine, $\mathrm{mg} / \mathrm{dL}$ & $1.07 \pm 0.34$ & $1.91 \pm 0.43$ & $2.74 \pm 0.60$ & $6.05 \pm 1.92$ & $\begin{array}{l}F=241.73 \\
P<0.001\end{array}$ \\
\hline $\begin{array}{l}\text { Glomerular filtration rate (GFR), } \\
\mathrm{mL} / \mathrm{min} / 1.7 \mathrm{~m}^{2}\end{array}$ & $86.13 \pm 11.47$ & $72.96 \pm 16.14$ & $41.59 \pm 12.45$ & $15.73 \pm 6.31$ & $\begin{array}{l}F=320.75 \\
P<0.001\end{array}$ \\
\hline \multicolumn{6}{|l|}{ Blood pressure $(\mathrm{mm} \mathrm{Hg})$} \\
\hline Systolic & $127.52 \pm 11.17$ & $136.63 \pm 7.85$ & $138.94 \pm 7.14$ & $152.74 \pm 9.47$ & $\begin{array}{l}F=64.99 \\
P<0.001\end{array}$ \\
\hline Diastolic & $81.50 \pm 6.87$ & $85.53 \pm 7.63$ & $87.53 \pm 9.02$ & $88.65 \pm 7.79$ & $\begin{array}{c}F=7.83 \\
P<0.001\end{array}$ \\
\hline Haemoglobin, g/dL & $12.79 \pm 1.39$ & $11.56 \pm 1.30$ & $9.59 \pm 1.71$ & $8.86 \pm 2.00$ & $\begin{array}{l}F=63.66 \\
P<0.001\end{array}$ \\
\hline Blood urea, mg/dL & $31.16 \pm 14.24$ & $49.66 \pm 9.72$ & $89.10 \pm 23.40$ & $128.98 \pm 32.41$ & $\begin{array}{l}F=192.86 \\
P<0.001\end{array}$ \\
\hline
\end{tabular}

prolidase activity $[6,9]$. However no one has reported on serum prolidase activity in ESRD with T2DM.

Thus, in the present study, we aimed to observe the correlation of blood glucose and creatinine to serum prolidase activity and oxidative stress in T2DM, diabetic nephropathy and in ESRD with T2DM, and assess the possibility of a new biomarker for the evaluation of kidney damage.

\section{Subjects and Methods}

This study was done at the Department of Biochemistry and Department of Nephrology, Institute of Medical Sciences, Banaras Hindu University, Varanasi, India. The study was ethically approved by institutional ethical committee and signed informed consent was taken from every subject.

2.1. Patients Selection. Total of 229 subjects of matched age and sex were selected. Out of 229, 50 subjects (F-16, M-34) who were patients of type-2 diabetes mellitus (T2DM) of ages between 25 and $76(53.34 \pm 14.68)$ years, 86 patients with diabetic nephropathy (F-39, M-47) of age range 28-76 $(52.34 \pm 12.89)$ years, 43 ESRD patients (F-19, M-24) caused by T2DM of age range $30-80(57.34 \pm 15.36)$ years old, and 50 healthy volunteers (F-20, M-30) of age 25-75 (52.64 \pm 18.76$)$ years old were included in the study. Healthy volunteers and patients with T2DM were considered as control-1 and control-2 group, respectively, whereas patients with diabetic nephropathy and ESRD were categorized as case-1 and case-2, respectively (Table 1).

Inclusion Criteria. Patients of T2DM, diabetic nephropathy, and ESRD attending outpatient department and admitted in the ward of nephrology, Sir Sunder Lal hospital, BHU, who agreed to participate in the study were included. Medical history, standard physical examination, and test of biochemical parameters (blood sugar, creatinine, and glomerular filtration rate) listed in Table 1 are used for selection and categorization of cases and controls.

Exclusion Criteria. Patients suffering from major infections like tuberculosis, HIV, and so forth, chronic heart failure, pregnant females, taking potent antioxidant, and history of alcohol intake were excluded from our study. Diabetic macroangiopathic complications (like coronary artery disease, peripheral vascular disease, and stroke) and acute myocardial infarction in diabetes groups were excluded.

2.2. Collection and Storage of Samples. Venous blood was collected in 2 vials (EDTA tube and plane tube). Blood in the EDTA tube was used for the estimation of glucose and hemoglobin, while blood in plane tube was allowed to clot and serum was separated by centrifugation at $3000 \mathrm{rpm}$ for $10 \mathrm{~min}$ at $4^{\circ} \mathrm{C}$. Serum samples for the measurement of serum prolidase activity, total oxidant status (TOS), and total 
antioxidant status (TAS) were stored at $-80^{\circ} \mathrm{C}$. Samples were thawed to room temperature before every assay, and repeated thaw was avoided.

2.3. Estimation of Serum Prolidase Activity. Diluting solution (contains $1 \mathrm{mM} \mathrm{MnCl}$ in $6 \mathrm{mM}$ tris $\mathrm{HCl}$ buffer), standard proline solution $(650 \mu \mathrm{mol} / \mathrm{L}$ in $0.45 \mathrm{~mol} / \mathrm{L}$ trichloroacetic acid), $94 \mathrm{mmol} / \mathrm{L}$ glycyl-l-proline solution $(94 \mathrm{mmol} / \mathrm{L}$ Gly1-Pro solution in $0.05 \mathrm{~mol} / \mathrm{L}$ Tris $\mathrm{HCl}$ buffer containing $1 \mathrm{mmol} / \mathrm{L}$ of $\mathrm{MnCl}_{2}(\mathrm{pH} 7.8-8.0)$ ), and Chinard's reagent $(600 \mathrm{~mL}$ of glacial acetic acid mixed with $400 \mathrm{~mL}$ of $6 \mathrm{~mol} / \mathrm{L}$ orthophosphoric acid and dissolved $25 \mathrm{~g}$ of ninhydrin in the mixture at $70^{\circ} \mathrm{C}$ temperature; for preparation of $6 \mathrm{~mol} / \mathrm{L}$ orthophosphoric acid, $407 \mathrm{~mL}$ of orthophosphoric acid (85\%, $d=1.7$ ) was added to $593 \mathrm{~mL}$ of distilled water) were prepared.

\section{Procedures}

The serum obtained from subjects were diluted six times with diluting solution and preincubated for 24 hours at $37^{\circ} \mathrm{C}$ for enzyme activation. The enzymatic reactions were carried out in two Eppendorf tubes and labeled as experimental and control. $100 \mu \mathrm{L}$ of Gly-l-Pro and $100 \mu \mathrm{L}$ of diluted preincubated serum were added in experimental tube, while control tubes contain only $100 \mu \mathrm{L}$ of diluted preincubated serum. Both tubes were incubated for 30 minutes at $37^{\circ} \mathrm{C}$. By adding of $1 \mathrm{~mL}$ of trichloroacetic acid $(0.45 \mathrm{~mol} / \mathrm{L})$ the reaction was checked. Followed by $100 \mu \mathrm{L}$ of diluted, nonincubated serum was added in control tube. After that centrifugation at $2000 \mathrm{rpm}$ for 5 minutes supernatant was separated and $0.5 \mathrm{~mL}$ was used for proline estimation.

For measurement of enzymatic reaction, four tubes were selected and labeled as blank tube, standard tube, experimental tube, and control tube. $1 \mathrm{~mL}$ of glacial acetic acid and $1 \mathrm{~mL}$ of Chinard's reagent were added in each tube. After this, $0.5 \mathrm{~mL}$ of supernatant was added in experimental tube and control tube. $0.5 \mathrm{~mL}$ of trichloroacetic acid $(0.45 \mathrm{~mol} / \mathrm{L})$ was added in blank tube and $0.5 \mathrm{~mL}$ of standard proline solution was added in standard tube. All four tubes were incubated in water bath at $90^{\circ} \mathrm{C}$ for 10 minutes and optical densities (OD) were taken at $515 \mathrm{~nm}$. Spectrophotometer was adjusted to zero with blank tube solution.

For the calculation of enzymatic activity we used the following Myara et al. [8] equation:

$$
\begin{array}{r}
\frac{E-C}{S} \times[S] \times 2.4=\mathrm{mmol} \cdot \mathrm{Min}^{-1} \cdot \mathrm{L}^{-1} \text { at } 37^{\circ} \mathrm{C}, \\
\mathrm{pH} 7.8-8.0,
\end{array}
$$

where $S$ : standard tube absorbance, $E$ : experimental tube absorbance, $C$ : control tube absorbance, and $[S]$ : substrate concentration in $\mathrm{mmol} / \mathrm{L}(94 \mathrm{mmol} / \mathrm{L})$.

3.1. Total Antioxidant Status (TAS) and Total Oxidant Status (TOS). TAS and TOS of serum were determined by using automated measurement methods developed by Erel $[15,16]$.
3.2. Oxidative Stress Index (OSI). OSI values were calculated according to the following formula [11]:

$$
\operatorname{OSI}(\mathrm{A})=\frac{\operatorname{TOS}\left(\mathrm{mmol} \mathrm{H}_{2} \mathrm{O}_{2} \text { Eq. } / \mathrm{L}\right)}{\operatorname{TAS}(\mu \mathrm{mol} \text { Trolox Eq. } / \mathrm{L})} .
$$

3.3. Glomerular Filtration Rate (GFR) Estimation. GFR was calculated according to following CKD-EPI creatinine equation [17]:

$$
\begin{aligned}
& \text { Estimated GFR }\left(\mathrm{mL} / \mathrm{min} / 1.73 \mathrm{~m}^{2}\right) \\
& =175 \times S_{\mathrm{cr}}^{-1.154} \\
& \times \text { age }^{-0.203} \times 1.212 \text { [if black] } \\
& \times 0.742 \text { [if female] } .
\end{aligned}
$$

This equation was originally designed to estimate glomerular filtration rate and expressed in $\mathrm{mL} / \mathrm{min} / 1.73 \mathrm{~m}^{2} . S_{\mathrm{cr}}=$ serum creatinine in $\mathrm{mg} / \mathrm{dL}$ and age in years were used in the equation.

Estimation of clinical parameters like creatinine, blood glucose (fasting blood sugar (FBS), and two hours postprandial blood sugar (PPBS)) and urea were done by commercial kits (creatinine by alkaline picrate method, blood glucose by glucose oxidase method, and urea by DAM method). Hemoglobin was estimated by hematology autoanalyser and blood pressure was measured by mercury sphygmomanometer.

3.4. Statistical Analysis. Parametric and nonparametric statistical methods, Student's $t$-test, ANOVA Student-NewmanKeuls test, and Pearson's correlation were used. $P$ value less than $0.05,0.01$, and 0.001 were considered as significant, highly significant, and very highly significant, respectively. Sensitivity, specificity, and all other statistical calculations were done by use of software SPSS 16.0 version. Inter- and intraassay $\%$ of coefficient of variations $(\mathrm{CV})$ was estimated for SPA (6.85 and 3.82\%), TAS (8.45 and $4.12 \%)$, and TOS (7.38 and $3.89 \%)$.

\section{Results}

4.1. Demography and Clinical Parameters for Controls and Cases. Demography and clinical parameters of controls and cases are tabulated in Table 1. One way ANOVA for glomerular filtration rate, serum creatinine $\left(S_{\mathrm{cr}}\right)$, fasting blood glucose (FBS), postprandial blood glucose (PPBS), systolic blood pressure, diastolic blood pressure, haemoglobin, and blood urea within and between groups (control-1, control-2, case-1, and case-2) were significant (all $P<0.001$; Table 1 ).

4.2. Serum Prolidase Activity (SPA) in Controls and Cases. SPA in control-1, control-2, case-1, and case-2 was observed as $55.72 \pm 7.90,60.18 \pm 7.85,68.56 \pm 11.09$, and $74.23 \pm$ $13.22 \mathrm{mmol} \mathrm{min}^{-1} \mathrm{~L}^{-1}$, respectively (Table 2 ). Thus SPA is significantly increased in case- 2 than in case-1, control-1, and control-2 $(P<0.001$; Table 2$)$. Differences of SPA between any two groups have significant values (all $P<0.05$; Table 3 ). 
TABLE 2: Representation of SPA, TAS, TOS, and OSI for cases and controls.

\begin{tabular}{lccccc}
\hline Subjects/parameters & $\begin{array}{c}\text { Control-1 } \\
(n=50)\end{array}$ & $\begin{array}{c}\text { Control-2 } \\
(n=50)\end{array}$ & $\begin{array}{c}\text { Case-1 } \\
(n=86)\end{array}$ & $\begin{array}{c}\text { Case-2 } \\
(n=43)\end{array}$ & $\begin{array}{c}\text { ANOVA } \\
(\text { Sig./F })\end{array}$ \\
\hline SPA & $55.72 \pm 7.90$ & $60.18 \pm 7.85$ & $68.56 \pm 11.09$ & $74.23 \pm 13.22$ & $F=32.14$ \\
$\left(\mathrm{mmol} \mathrm{min}^{-1} \mathrm{~L}^{-1}\right)$ & $(R=47.32$ to 78.34$)$ & $(R=45$ to 82$)$ & $(R=47.49$ to 89.42$)$ & $(R=56$ to 96$)$ & $P<0.001$ \\
TAS & $1.97 \pm 0.51$ & $1.82 \pm 0.43$ & $1.42 \pm 0.39$ & $1.20 \pm 0.45$ & $F=32.99$ \\
$(\mathrm{mmol}$ Trolox Eq/L) & $(R=0.81$ to 2.91$)$ & $(R=0.95$ to 2.76$)$ & $(R=0.78$ to 2.25$)$ & $(R=0.63$ to 1.98$)$ & $P<0.001$ \\
TOS & $13.82 \pm 2.14$ & $17.54 \pm 2.46$ & $20.13 \pm 3.75$ & $22.21 \pm 3.66$ & $F=64.47$ \\
$\left(\mu \mathrm{mol} \mathrm{H}_{2} \mathrm{O}_{2} \mathrm{Eq} / \mathrm{L}\right)$ & $(R=9.88$ to 17.71$)$ & $(R=12.74$ to 28.91$)$ & $(R=12.50$ to 34.0$)$ & $(R=15.34$ to 31.0$)$ & $P<0.001$ \\
OSI & $8.02 \pm 4.21$ & $10.58 \pm 4.58$ & $16.04 \pm 7.58$ & $22.09 \pm 10.21$ & $F=37.21$ \\
$($ arbitrary unit $)$ & $(R=3.41$ to 21.86$)$ & $(R=5.04$ to 29.50$)$ & $(R=5.55$ to 42.50$)$ & $(R=7.87$ to 47.69$)$ & $P<0.001$ \\
\hline
\end{tabular}

TABLE 3: Representation of Student-Newman-Keuls test's $P$ value for different variable and multiple comparison groups.

\begin{tabular}{|c|c|c|c|c|c|c|}
\hline \multirow{2}{*}{ Variables } & \multicolumn{6}{|c|}{$P$ values for groups compared (according to Student-Newman-Keuls test) } \\
\hline & $\begin{array}{c}\text { Control-1 versus } \\
\text { Control-2 }\end{array}$ & $\begin{array}{c}\text { Control-1 versus } \\
\text { case-1 }\end{array}$ & $\begin{array}{l}\text { Control-1 versus } \\
\text { case- } 2\end{array}$ & $\begin{array}{c}\text { Control-2 versus } \\
\text { case-1 }\end{array}$ & $\begin{array}{c}\text { Control-2 versus } \\
\text { Case- } 2\end{array}$ & $\begin{array}{c}\text { Case-1 versus } \\
\text { Case-2 }\end{array}$ \\
\hline SPA & 0.031 & $<0.001$ & $<0.001$ & $<0.001$ & $<0.001$ & 0.004 \\
\hline TAS & 0.091 & $<0.001$ & $<0.001$ & $<0.001$ & $<0.001$ & 0.007 \\
\hline TOS & $<0.001$ & $<0.001$ & $<0.001$ & $<0.001$ & $<0.001$ & 0.001 \\
\hline OSI & 0.07 & $<0.001$ & $<0.001$ & $<0.001$ & $<0.001$ & $<0.001$ \\
\hline GFR & $<0.001$ & $<0.001$ & $<0.001$ & $<0.001$ & $<0.001$ & $<0.001$ \\
\hline Serum Cr & $<0.001$ & $<0.001$ & $<0.001$ & $<0.001$ & $<0.001$ & $<0.001$ \\
\hline FBS & $<0.001$ & $<0.001$ & $<0.001$ & 0.722 & 0.001 & 0.001 \\
\hline PPBS & $<0.001$ & $<0.001$ & $<0.001$ & 0.943 & 0.022 & 0.009 \\
\hline BP Systolic & $<0.001$ & $<0.001$ & $<0.001$ & 0.139 & $<0.001$ & $<0.001$ \\
\hline BP Diastolic & 0.013 & $<0.001$ & $<0.001$ & 0.164 & 0.064 & 0.459 \\
\hline $\mathrm{Hb}$ & $<0.001$ & $<0.001$ & $<0.001$ & $<0.001$ & $<0.001$ & 0.016 \\
\hline B Urea & $<0.001$ & $<0.001$ & $<0.001$ & $<0.001$ & $<0.001$ & $<0.001$ \\
\hline
\end{tabular}

$P$ values $>0.05$ considered as nonsignificant, while $P$ values $<0.05,<0.01$, and $<0.001$ considered as significant, highly significant and very highly significant values, respectively.

4.3. Total Antioxidant Status (TAS) in Controls and Cases. TAS in case-2 $(1.20 \pm 0.45 \mathrm{mmol}$ Trolox Eq./L) was significantly decreased than in case-1, control-2 and control$1(1.42 \pm 0.39,1.82 \pm 0.43$, and $1.97 \pm 0.51 \mathrm{mmol}$ Trolox Eq/L, resp. $)(P<0.001$; Table 2$)$. TAS was nonsignificantly decreased in control-2 than in control-1 $(P=0.091)$, while differences of TAS for any other two groups were of significant value (all $P<0.01$; Table 3 ).

4.4. Total Oxidant Status (TOS) in Controls and Cases. TOS in case-2 $\left(22.21 \pm 3.66 \mu \mathrm{mol} \mathrm{H}_{2} \mathrm{O}_{2}\right.$ Eq./L) was significantly increased than in case-1, control-2, and control-1 (20.13 \pm 3.75 , $17.54 \pm 2.46$, and $13.82 \pm 2.14 \mu \mathrm{mol} \mathrm{H}_{2} \mathrm{O}_{2}$ Eq./L, resp. $)(P<$ 0.001; Table 2). The differences of TOS for any two groups were of significant value $(P<0.001$; Table 3$)$.

4.5. Oxidative Stress Index (OSI) in Controls and Cases. OSI in case-2 $(22.09 \pm 10.21)$ was significantly increased than in case-1 (16.04 \pm 7.58$)$, control-1 $(8.02 \pm 4.21)$, and control$2(10.58 \pm 4.58)(P<0.001$; Table 2$)$. OSI in control-2 was nonsignificantly increased than in control-1 $(P=0.07$, Table 3), while differences in OSI for any other two groups were significant (all $P<0.001$; Table 3 ).
4.6. Correlative Values. Correlative values of fasting blood sugar (FBS) and creatinine (Cr) with SPA, TOS, TAS, and OSI are tabulated in Table 4. Nonsignificant correlation was observed between FBS and SPA and TOS, and TAS, and OSI in control-1, while significant correlation was observed in control-2, case-1, and case-2. Creatinine was nonsignificantly correlated to SPA, TOS, TAS, and OSI in control-1, while significant correlation was observed in control-2 and case-1 (Table 4 ). Increased creatinine in case- 2 was positively correlated to SPA $(P<0.001)$, while nonsignificant correlation was observed between creatinine and TOS and TAS and OSI (Table 4).

4.7. Sensitivity and Specificity of SPA, TOS, TAS, and OSI. DN and ESRD both are different stages of kidney damage. Thus for prediction of kidney damage values of area under the receiver operating characteristic curve (AUROC), sensitivity, and specificity for SPA, TOS, TAS, and OSI were tabulated in Table 5 and Figure 1.

\section{Discussion}

Out of the 229 patients enrolled for the study, 94 were females and 135 were males. As shown in Table 1, mean age group of 
TABLE 4: Representation of Pearson's correlation values for different comparison groups. FBS was nonsignificantly correlated to SPA, TOS, TAS, and OSI in control-1, while significantly correlated in control-2, case-1, and case-2. Nonsignificant correlation was observed between creatinine and SPA, TOS, TAS, and OSI in control-1, while significant in control-2 and case-1.

\begin{tabular}{|c|c|c|c|c|}
\hline \multirow{3}{*}{ Correlative variables } & \multicolumn{2}{|c|}{ Pearson's correlation values for controls } & \multicolumn{2}{|c|}{ Pearson's correlation values for cases } \\
\hline & Control-1 & Control-2 & Case-1 & Case-2 \\
\hline & $r$-value & $r$-value & $r$-value & $r$-value \\
\hline FBS Vs SPA & $0.075^{\#}$ & $0.801^{* * *}$ & $0.674^{* * *}$ & $0.820^{* * *}$ \\
\hline FBS Vs TOS & $0.025^{\#}$ & $0.635^{* * *}$ & $0.475^{* * *}$ & $0.425^{* *}$ \\
\hline FBS Vs TAS & $-0.074^{\#}$ & $-0.612^{* * *}$ & $-0.759^{* * *}$ & $-0.580^{* * *}$ \\
\hline FBS Vs OSI & $0.030^{\#}$ & $0.591^{* * *}$ & $0.726^{* * *}$ & $0.459^{* *}$ \\
\hline Cr Vs SPA & $-0.024^{\#}$ & $0.837^{* * *}$ & $0.831^{* * *}$ & $0.617^{* * *}$ \\
\hline Cr Vs TOS & $-0.066^{\#}$ & $0.648^{* * *}$ & $0.648^{* * *}$ & $0.125^{\#}$ \\
\hline Cr Vs TAS & $-0.043^{\#}$ & $-0.610^{* * *}$ & $-0.718^{* * *}$ & $-0.256^{\#}$ \\
\hline Cr Vs OSI & $0.002^{\#}$ & $0.597^{* * *}$ & $0.699^{* * *}$ & $0.218^{\#}$ \\
\hline DD Vs SPA & Nil & $0.862^{* * *}$ & $0.887^{* * *}$ & $0.766^{* * *}$ \\
\hline DD Vs TOS & Nil & $0.441^{* *}$ & $0.591^{* * *}$ & $0.324^{*}$ \\
\hline DD Vs OSI & Nil & $0.446^{* *}$ & $0.745^{* * *}$ & $0.363^{*}$ \\
\hline DD Vs TAS & Nil & $-0.391^{* *}$ & $-0.859^{* * *}$ & $-0.472^{* *}$ \\
\hline
\end{tabular}

${ }^{\#}$ Nonsignificant value; ${ }^{*}$ significant value at $P<0.05 ;{ }^{* *}$ significant value at $P<0.01 ;{ }^{* * *}$ significant value at $P<0.001 ; \mathrm{DD}$ : duration of T2DM.

TABLE 5: Values of SPA, TOS, TAS, and OSI sensitivity and specificity for prediction of kidney damage (including both values of case-1 and case-2) with respect to control-1 and control-2.

\begin{tabular}{|c|c|c|c|c|c|}
\hline Diagnosis & $\begin{array}{l}\text { Cutoff level for kidney damage } \\
\text { (DN or ESRD or both) }\end{array}$ & Sensitivity (\%) & Specificity (\%) & AUROC (95\% CI) & $\begin{array}{l}\text { Asymptotic } \\
\text { Sig. }\end{array}$ \\
\hline $\begin{array}{l}\text { SPA } \\
\left(\mathrm{mmol} \mathrm{min}^{-1} \mathrm{~L}^{-1}\right)\end{array}$ & $\geq 60.78$ & 76 & 66 & $0.798(0.741-0.855)$ & $<0.001$ \\
\hline $\begin{array}{l}\text { TOS } \\
\left(\mu \mathrm{mol} \mathrm{H}_{2} \mathrm{O}_{2} \mathrm{Eq} / \mathrm{L}\right)\end{array}$ & $\geq 16.64$ & 89.10 & 60 & $0.87(0.825-0.915)$ & $<0.001$ \\
\hline $\begin{array}{l}\text { TAS } \\
(\mathrm{mmol} \text { Trolox Eq/L) }\end{array}$ & $\leq 0.81$ & 89.10 & 2 & $0.198(0.141-0.255)$ & $<0.001$ \\
\hline $\begin{array}{l}\text { OSI } \\
\text { (arbitrary unit) }\end{array}$ & $\geq 10.24$ & 80.60 & 67 & $0.838(0.787-0.889)$ & $<0.001$ \\
\hline
\end{tabular}

AUROC: area under the receiver operating characteristic curve; CI: confidence interval.

control-1, control-2, and case-1 is nearly the same, while the mean age for the group case- 2 is slightly higher. With increase in the duration of the disease, decline in kidney function $(\downarrow$ in GFR and haemoglobin and $\uparrow$ in serum creatinine and urea along with elevated blood pressure) is clearly seen and it is statistically significant also.

Serum prolidase activity, TOS, TAS, and OSI are recognized as oxidative stress markers. In our study, patients with ESRD have increased SPA, TOS, and OSI and decreased TAS than patients with DN, T2DM, and healthy volunteers $(P<0.001)$ (Table 2$)$. Patients with T2DM and DN also have increased oxidative stress than healthy volunteers and the increase is also seen with the progression of the disease.

Erbagci et al, [9], have reported that serum prolidase activity was decreased in patients with T2DM than healthy volunteers. On contrary, experimental results of Uzar et al [6], showed that serum prolidase activity was increased with increase in oxidative stress in patients with diabetes than normal subjects. Our present study shows that increase in serum prolidase activity and TOS were significant (all $P<$ $0.05)$ and increase in OSI was non-significant $(P=0.07)$, while TAS was non-significantly decreased $(P=0.091)$ in patients with T2DM than healthy volunteers (Table 3 ). Erbagci et al. [9], has reported that differences in prolidase activity between with and without diabetic nephropathy were non-significant. In present study, we found significant increase in serum prolidase activity, TOS, OSI and significant decrease in TAS in patients with DN and ESRD than healthy volunteers (all $P<0.001$, Table 3 ).

In patients with $\mathrm{T} 2 \mathrm{DM}$ and $\mathrm{DN}$, oxygen free radicals increase with continuous elevation of glucose and this leads to increased oxidative stress $[18,19]$. In our present study we observed that mean of duration of diabetes continuously increases as the disease progresses from T2DM to DN to ESRD (Table 1). This increase in duration of diabetes positively correlates with increase in TOS and OSI (all $P<0.05$ ), while increase in duration of diabetes negatively correlates with decrease in TAS (all $P<0.01$; Table 4). Observed SPA strongly positively correlated to duration of diabetes in patients with T2DM, DN, and ESRD (all $P<0.001$; Table 4). Thus it seems that with increase in duration of the disease, continuous increase in oxidative stress is observed and that 


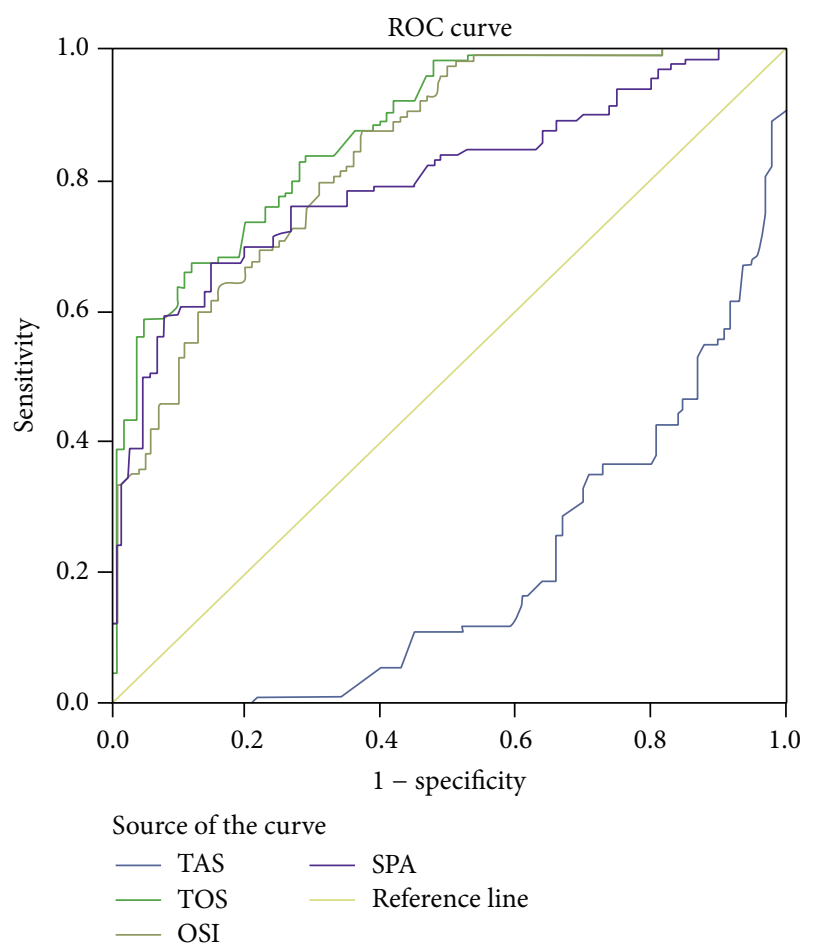

Area under the curve
\begin{tabular}{|c|c|c|c|c|c|}
\hline $\begin{array}{c}\text { Test } \\
\text { result } \\
\text { variable } \\
(\mathrm{s})\end{array}$ & Area & Std. error & & & $\begin{array}{c}\text { Asymptotic } 95 \% \text { confidence } \\
\text { interval }\end{array}$ \\
\hline TAS & 0.198 & 0.029 & 0.000 & 0.141 & 0.255 \\
TOS & 0.870 & 0.023 & 0.000 & 0.825 & 0.915 \\
OSI & 0.838 & 0.026 & 0.000 & 0.787 & 0.889 \\
SPA & 0.798 & 0.029 & 0.000 & 0.741 & 0.855 \\
\hline
\end{tabular}

The test result variable (s): TAS, TOS, OSI, and SPA has at least one tie between the positive actual state group and the negative actual state group. Statistics may be biased.

a: under the nonparametric assumption

b: null hypothesis: true area $=0.5$

FIGURE 1: Receiver operating characteristic (ROC) curve of SPA, TOS, TAS, and OSI at cutoff value $\geq 60.78 \mathrm{mmol} \mathrm{min}^{-1} \mathrm{~L}^{-1}$, $\geq 16.64 \mu \mathrm{mol} \mathrm{H}_{2} \mathrm{O}_{2}$ Eq./L, $\leq 0.81 \mathrm{mmol}$ Trolox Eq./L, and $\geq 10.24 \mathrm{AU}$, respectively, for the prediction of kidney damage (either DN or ESRD or both).

might be the one mechanism for pathogenesis of progression of the disease.

Chronic high blood glucose leads to glucose toxicity, which is responsible for chronic oxidative stress in patients with T2DM $[20,21]$. In our previous studies, we showed that increased oxidative stress is related to increased inflammatory cytokines, Helicobacter infection, and bacterial meningitis $[22,23]$. In present study it is shown that SPA, TOS, and OSI were significantly increased and TAS was significantly decreased in patients with T2DM, DN, and ESRD than healthy subjects. This increase in SPA, TOS, and OSI and decrease in TAS were significantly correlated to chronic high blood glucose in T2DM, DN, and ESRD (all $P<0.01$; Table 4).

Creatinine is correlated to oxidative stress marker. It has been previously reported that increased creatinine is correlated to increased glucose, which activates oxidative stress in patients with T2DM [24]. Terawaki et al. [25] and Huang et al. [26] reported that increased creatinine was significantly correlated to increased oxidative stress in patients with chronic kidney disease and end stage renal disease, respectively. In present study, significant correlation has been observed between creatinine and SPA and TOS and TAS and OSI in patients with T2DM and DN. In case of patients with ESRD, creatinine was significantly correlated to SPA, while nonsignificantly correlated to TOS, TAS, and OSI (Table 4).

After observing the correlation between serum glucose and creatinine with the oxidative markers, we evaluated these markers in reference to their role in the predictive value for kidney damage. In the present study SPA, TOS, TAS, and OSI sensitivity and specificity were observed for prediction of kidney damage. SPA value at $\geq 60.78 \mathrm{mmol} \mathrm{Min}^{-1} \mathrm{~L}^{-1}$ predicted $76 \%$ sensitivity with $66 \%$ of specificity for kidney damage (either DN or ESRD or both). TOS at $\geq 16.64 \mu \mathrm{mol}$ $\mathrm{H}_{2} \mathrm{O}_{2}$ Eq./L, TAS at $\leq 0.81 \mathrm{mmol}$ Trolox Eq./L, and OSI at $\geq 10.24$ were predicted $89.10 \%$ sensitivity with $60 \%$ specificity, $89.10 \%$ sensitivity with $2 \%$ specificity, and $80.60 \%$ sensitivity with $67 \%$ specificity for kidney damage (either DN or ESRD or both), respectively (Table 5 and Figure 1). It shows that increased values of SPA, TOS, and OSI and decreased TAS have more sensitivity rather than specificity for prediction of kidney damage. Thus it seems that increased SPA, TOS, and OSI and decreased TAS can be used as biomarkers for prediction of kidney damage.

This study revealed that serum prolidase activity and oxidative stress were significantly increased in patients with DN and ESRD than patients with T2DM and healthy volunteers. The same pattern was also obtained for T2DM with respect to healthy volunteers with significant differences. Blood glucose and creatinine were correlated to oxidative stress markers (TOS, TAS, and OSI) and serum prolidase activity in patients with T2DM, DN, and ESRD. It is concluded that serum prolidase activity, TOS, TAS, and OSI at cutoff values $\geq 60.78 \mathrm{mmol} \mathrm{Min}^{-1} \mathrm{~L}^{-1}, \geq 16.64 \mu \mathrm{mol} \mathrm{H}_{2} \mathrm{O}_{2}$ Eq./L, $\leq 0.81 \mathrm{mmol}$ Trolox Eq./L, and $\geq 10.24 \mathrm{AU}$, respectively, can be use as biomarkers for prediction and diagnosis of kidney damage (either DN or ESRD or both).

\section{Conflict of Interests}

The authors have declared that no conflict of interests exists.

\section{Acknowledgments}

The authors are thankful to all the subjects who enrolled, signed consent form, and provided positive cooperation to this study. Fellowship (IMS-UGC JRF) provided to Akhilesh Kumar Verma from Institute of Medical Sciences, Banaras Hindu University, Varanasi, Uttar Pradesh, India, has been gratefully acknowledged. 


\section{References}

[1] R. E. Gilbert and M. E. Cooper, "The tubulointerstitium in progressive diabetic kidney disease: more than an aftermath of glomerular injury?" Kidney International, vol. 56, no. 5, pp. 1627-1637, 1999.

[2] C. E. Mogensen, C. K. Christensen, and E. Vittinghus, "The stages in diabetic renal disease: with emphasis on the stage of incipient diabetic nephropathy," Diabetes, vol. 32, no. 2, pp. 6478, 1983.

[3] J. Pickup and G. Williams, Text Book of Diabetes, Blackwell Science, 2nd edition, 1997.

[4] C. R. Kahn, G. C. Weir, G. L. King, A. M. Jacobson, A. C. Moses, and R. J. Smith, Joslin's Diabetes Mellitus, Indian ed., Lippincott Williams \& Wilkins, Philadelphia, Pa, USA, 14th edition, 2005.

[5] A. C. Maritim, R. A. Sanders, and J. B. Watkins III, "Diabetes, oxidative stress, and antioxidants: a review," Journal of Biochemical and Molecular Toxicology, vol. 17, no. 1, pp. 24-38, 2003.

[6] E. Uzar, Y. Tamam, O. Evliyaoglu et al., "Serum prolidase activity and oxidative status in patients with diabetic neuropathy," Neurological Sciences, vol. 33, no. 4, pp. 875-880, 2012.

[7] G. Zanaboni, K. M. Dyne, A. Rossi, V. Monafo, and G. Cetta, "Prolidase deficiency: biochemical study of erythrocyte and skin fibroblast prolidase activity in Italian patients.," Haematologica, vol. 79, no. 1, pp. 13-18, 1994.

[8] I. Myara, A. Myara, M. Mangeot, M. Fabre, C. Charpentier, and A. Lemonnier, "Plasma prolidase activity: a possible index of collagen catabolism in chronic liver disease," Clinical Chemistry, vol. 30, no. 2, pp. 211-215, 1984.

[9] A. B. Erbagci, M. Araz, A. Erbağci, M. Tarakçioğlu, and E. S. Namiduru, "Serum prolidase activity as a marker of osteoporosis in type 2 diabetes mellitus," Clinical Biochemistry, vol. 35, no. 4, pp. 263-268, 2002.

[10] M. Savas, E. Yeni, H. Celik et al., "The association of serum prolidase activity and erectile dysfunction," Journal of Andrology, vol. 31, no. 2, pp. 146-154, 2010.

[11] S. Kumari, A. K. Verma, S. Rungta, R. Mitra, R. Srivastava, and N. Kumar, "Serum prolidase activity, oxidant and anti-oxidant status in non-ulcer dyspepsia and healthy volunteers," ISRN Biochemistry, vol. 2013, Article ID 182601, 6 pages, 2013.

[12] M. Bergmann and J. S. Fruton, "On proteolytic enzymes, XII, regarding the specificity of aminopeptidase and carboxypeptidase, a new type of enzyme in the intestinal tract," The Journal of Biological Chemistry, vol. 117, pp. 189-202, 1937.

[13] A. Surazynski, W. Miltyk, J. Palka, and J. M. Phang, "Prolidasedependent regulation of collagen biosynthesis," Amino Acids, vol. 35, no. 4, pp. 731-738, 2008.

[14] J. A. Palka and J. M. Phang, "Prolidase activity in fibroblasts is regulated by interaction of extracellular matrix with cell surface integrin receptors," Journal of Cellular Biochemistry, vol. 67, pp. 166-175, 1997.

[15] O. Erel, "A novel automated method to measure total antioxidant response against potent free radical reactions," Clinical Biochemistry, vol. 37, no. 2, pp. 112-119, 2004.

[16] O. Erel, "A new automated colorimetric method for measuring total oxidant status," Clinical Biochemistry, vol. 38, no. 12, pp. 1103-1111, 2005.

[17] A. S. Levey, L. A. Stevens, C. H. Schmid et al., "A new equation to estimate glomerular filtration rate," Annals of Internal Medicine, vol. 150, no. 9, pp. 604-612, 2009.
[18] K. Susztak, A. C. Raff, M. Schiffer, and E. P. Böttinger, "Glucoseinduced reactive oxygen species cause apoptosis of podocytes and podocyte depletion at the onset of diabetic nephropathy," Diabetes, vol. 55, no. 1, pp. 225-233, 2006.

[19] R. P. Robertson, J. Harmon, P. O. T. Tran, and V. Poitout, “ $\beta$-cell glucose toxicity, lipotoxicity, and chronic oxidative stress in type 2 diabetes," Diabetes, vol. 53, supplement 1, pp. S119-S124, 2004.

[20] S. Shah, M. Iqbal, J. Karam, M. Salifu, and S. I. McFarlane, "Oxidative stress, glucose metabolism, and the prevention of type 2 diabetes: pathophysiological insights," Antioxidants and Redox Signaling, vol. 9, no. 7, pp. 911-929, 2007.

[21] R. P. Robertson and J. S. Harmon, "Diabetes, glucose toxicity, and oxidative stress: a case of double jeopardy for the pancreatic islet $\beta$ cell," Free Radical Biology and Medicine, vol. 41, no. 2, pp. 177-184, 2006.

[22] R. Srivastava, R. Lohokare, and R. Prasad, "Oxidative stress in children with bacterial meningitis," Journal of Tropical Pediatrics, vol. 59, no. 4, pp. 305-308, 2013.

[23] R. Srivastava, A. Kashyap, M. Kumar, G. Nath, and A. K. Jain, "Mucosal IgA \& IL-1 $\beta$ in helicobacter pylori infection," Indian Journal of Clinical Biochemistry, vol. 28, no. 1, pp. 19-23, 2013.

[24] L. Monnier, E. Mas, C. Ginet et al., "Activation of oxidative stress by acute glucose fluctuations compared with sustained chronic hyperglycemia in patients with type 2 diabetes," Journal of the American Medical Association, vol. 295, no. 14, pp. 1681-1687, 2006.

[25] H. Terawaki, K. Yoshimura, T. Hasegawa et al., “Oxidative stress is enhanced in correlation with renal dysfunction: examination with the redox state of albumin," Kidney international, vol. 66, no. 5, pp. 1988-1993, 2004.

[26] K.-C. Huang, C.-C. Yang, K.-T. Lee, and C.-T. Chien, "Reduced hemodialysis-induced oxidative stress in end-stage renal disease patients by electrolyzed reduced water," Kidney International, vol. 64, no. 2, pp. 704-714, 2003. 

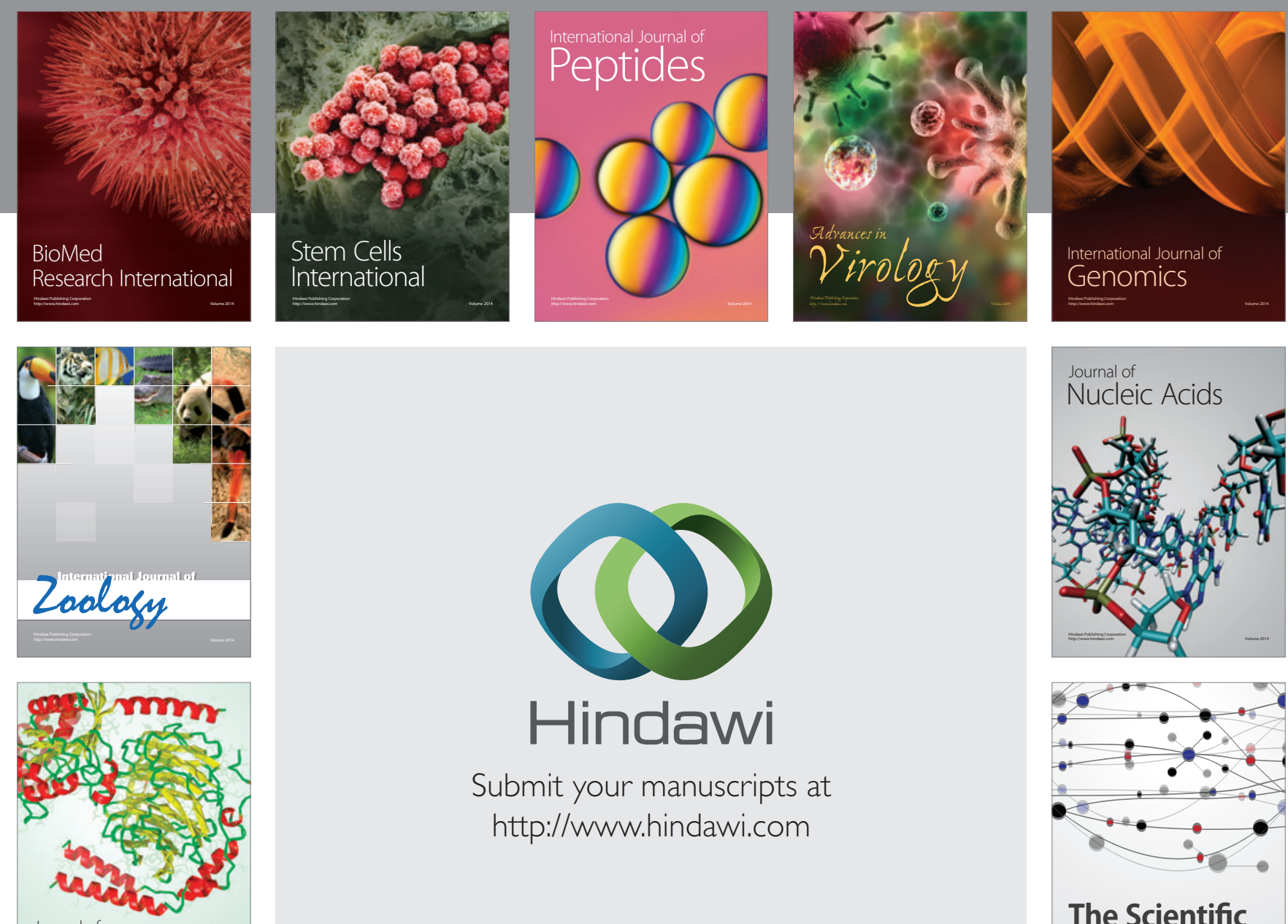

Submit your manuscripts at

http://www.hindawi.com

Journal of
Signal Transduction
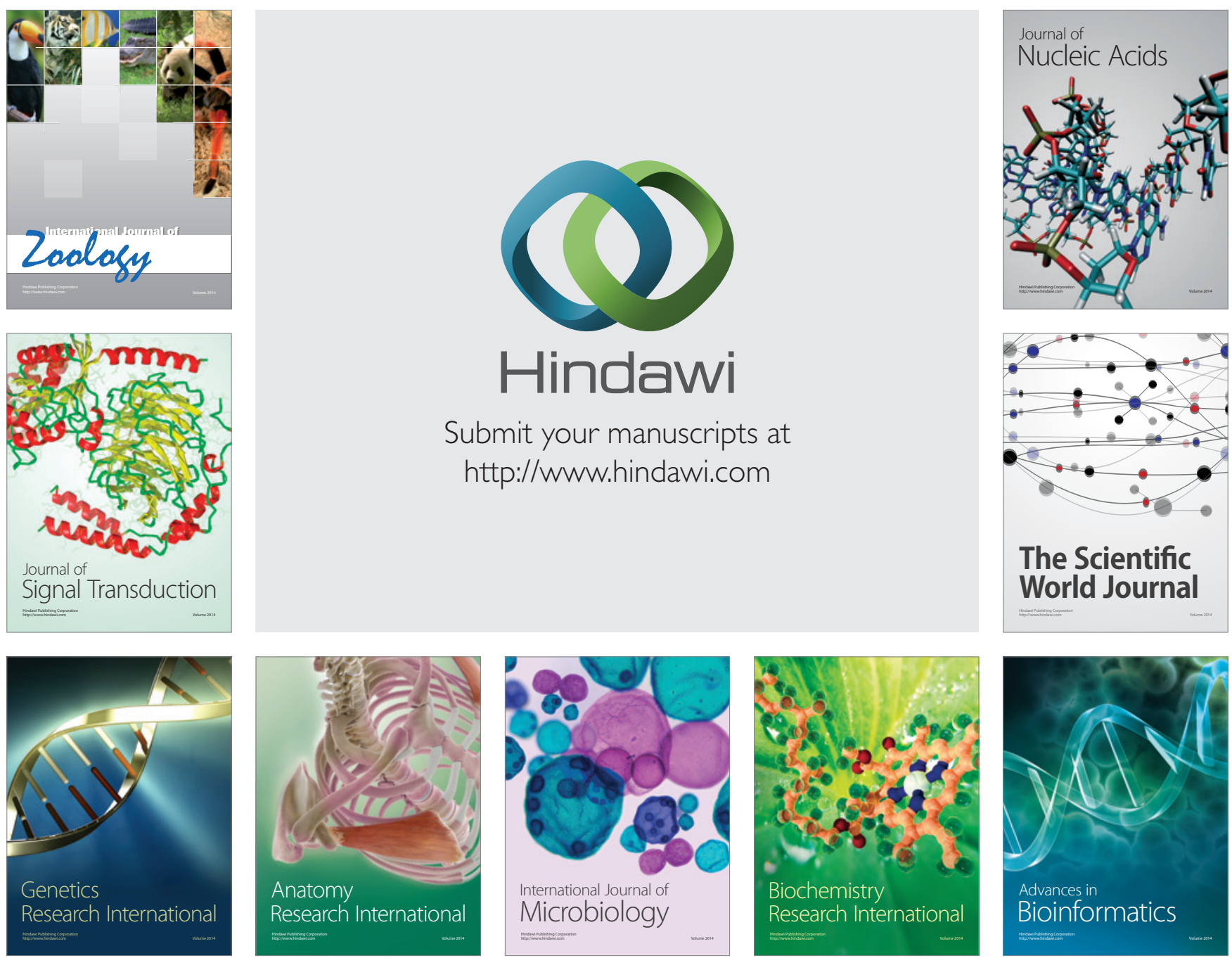

The Scientific World Journal
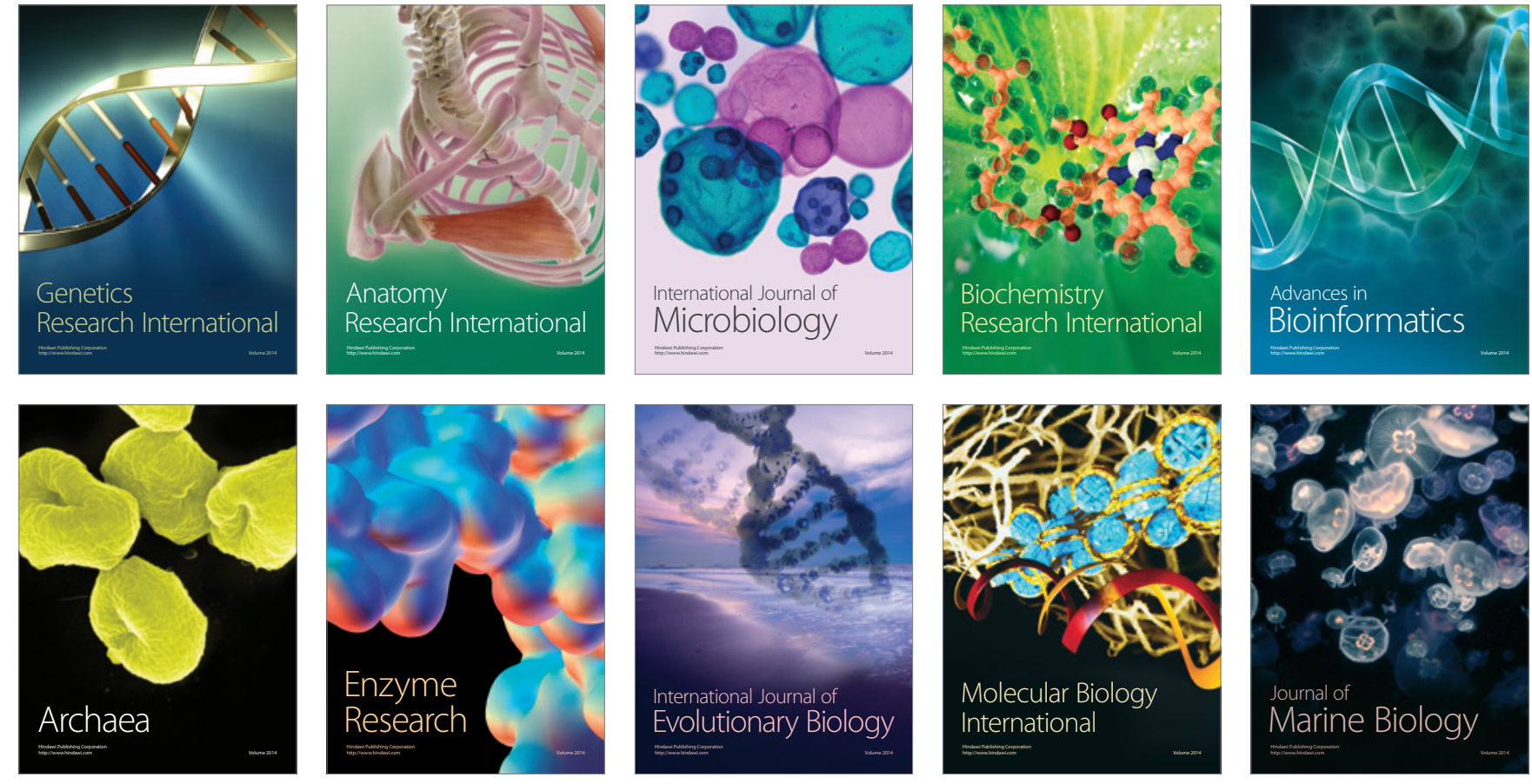